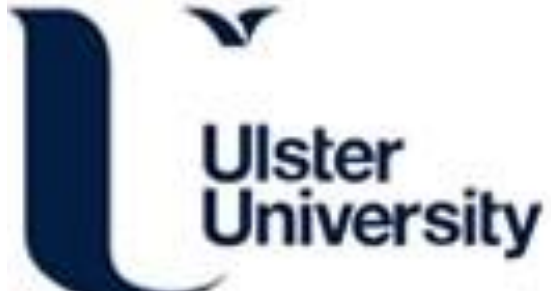

\section{Pressurization of Bone Cement under Standard, Flanged and Custom Acetabular Components for Total Hip Replacement}

Beverland, DE., Kernohan, WG., Nixon, JR., Orr, JF., \& Watson, P. (1993). Pressurization of Bone Cement under Standard, Flanged and Custom Acetabular Components for Total Hip Replacement. Proceedings of the Institution of Mechanical Engineers, Part H: Journal of Engineering in Medicine, 207(1), 19-23. https://doi.org/10.1243/PIME_PROC_1993_207_264_02

Link to publication record in Ulster University Research Portal

\section{Published in:}

Proceedings of the Institution of Mechanical Engineers, Part H: Journal of Engineering in Medicine

Publication Status:

Published (in print/issue): 01/03/1993

DOI:

10.1243/PIME_PROC_1993_207_264_02

\section{Document Version}

Publisher's PDF, also known as Version of record

\section{General rights}

Copyright for the publications made accessible via Ulster University's Research Portal is retained by the author(s) and / or other copyright owners and it is a condition of accessing these publications that users recognise and abide by the legal requirements associated with these rights.

\section{Take down policy}

The Research Portal is Ulster University's institutional repository that provides access to Ulster's research outputs. Every effort has been made to ensure that content in the Research Portal does not infringe any person's rights, or applicable UK laws. If you discover content in the Research Portal that you believe breaches copyright or violates any law, please contact pure-support@ulster.ac.uk. 


\section{Proceedings of the Institution of Mechanical Engineers, Part $\mathrm{H}$ : Journal of Engineering in Medicine \\ http://pih.sagepub.com/}

\section{Pressurization of Bone Cement under Standard, Flanged and Custom Acetabular Components for Total Hip Replacement \\ D E Beverland, W G Kernohan, J R Nixon, J F Orr and P Watson \\ Proceedings of the Institution of Mechanical Engineers, Part H: Journal of Engineering in Medicine 1993 207: 19 DOI: 10.1243/PIME_PROC_1993_207_264_02 \\ The online version of this article can be found at: \\ http://pih.sagepub.com/content/207/1/19}

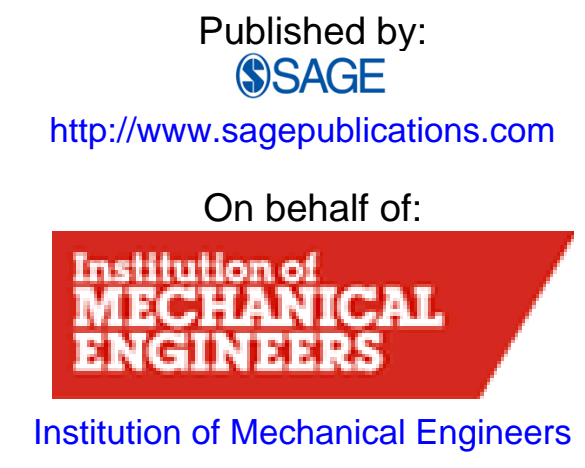

Additional services and information for Proceedings of the Institution of Mechanical Engineers, Part H: Journal of Engineering in Medicine can be found at:

Email Alerts: http://pih.sagepub.com/cgi/alerts

Subscriptions: http://pih.sagepub.com/subscriptions

Reprints: http://www.sagepub.com/journalsReprints.nav

Permissions: http://www.sagepub.com/journalsPermissions.nav

Citations: http://pih.sagepub.com/content/207/1/19.refs.html

>> Version of Record - Mar 1, 1993

What is This? 


\title{
Pressurization of bone cement under standard, flanged and custom acetabular components for total hip replacement
}

\author{
D E Beverland, MB, BCh, BAO, FRCS, MD, BOA, BMA \\ Musgrave Park Hospital, Belfast \\ W G Kernohan, PhD, CPhys, MInstP, FIMA, BOA, BORS, IPSM/HPA, IOP, IMA \\ Department of Orthopaedic Surgery, Queen's University of Belfast
}

J R Nixon, MChOrth, FRCS, FRCSI, BOA

Musgrave Park Hospital, Belfast

J F Orr, BSc, PhD, CEng, MIMechE

Department of Mechanical and Manufacturing Engineering, Queen's University of Belfast

P Watson, BSc, PhD, MemASME, MBES, MISPO

Musgrave Park Hospital, Belfast

\begin{abstract}
Custom acetabular components are proposed to achieve uniform cement mantles, even in irregular acetabula presented at revision, in order to enhance fixation. One aim of developing custom components was to permit pressurization of bone cement by the components at insertion and maintain the pressure during polymerization. $A$ model acetabulum was set up for the insertion of standard, flanged and custom components under constant force. Cement pressure was measured at the floor of the acetabulum by means of a piezoelectric diaphragm transducer. Polythene tubes were inserted in the model acetabular walls to estimate penetration of cement into cancellous bone.

Insertion of the standard and flanged components caused cement pressures up to $106 \mathrm{kPa}$ which decayed to less than $21 \mathrm{kPa}$ as cement escaped at the rim and the components came into contact with the acetabulum. The custom component maintained a pressure of over 60 $\mathrm{kPa}$ during polymerization from an initial pressure of $105 \mathrm{kPa}$ and examination of cement mantles on removal showed no evidence of contact. The custom component also showed enhanced penetration of cement, especially around the rim of the acetabulum. It is concluded that the custom component design achieves higher cement pressures and that better fixation will result.
\end{abstract}

\section{INTRODUCTION}

Acrylic bone cement has been used in joint replacement surgery for many years (1). It has long been appreciated that the cement is not an adhesive but rather acts as a filler and grouting agent. The quality of fixation of the components can be improved through improved techniques in handling and insertion of the cement, and in careful preparation of the bone bed $(2,3)$.

Following preparation and cleaning of the bone bed, cement should be introduced and pressurized. This may be achieved by pressurization of the liquid cement in the acetabulum prior to insertion of the prosthesis (4). Alternatively, the prosthesis itself may be modified to create pressurization of the cement during insertion. The flanged Charnley acetabular component is of the first type (5), the thin polyethylene flange being cut to the appropriate size and shape of the acetabulum. If the cement is pressurized prior to insertion of the flanged component the flange can help to maintain the pressure during polymerization (6).

In revision hip surgery, after acetabular loosening has occurred, the quality of bone available is often smooth and less receptive to cement injection techniques. In addition bone loss can occur, creating large irregular cavities in which standard components do not achieve satisfactory filling of the defect. Attempts to ream the

The MS was received on 27 November 1992 and was accepted for publication on 8 March 1993 defect to a hemispherical shape may result in further loss of bone stock.

This study set out to investigate the effect of using custom-made polyethylene acetabular components on cement pressurization in a simulated defect. Such components, if adopted for clinical use, would fill much of the void in a controlled and accurate way and should result in a more uniform predetermined cement mantle. Improved pressurization would therefore take place and a more durable implant fixation would be achieved.

\section{METHOD}

The experiments undertaken comprised a comparative study of pressures generated in, and the penetration of, cement around three acetabular component designs when inserted in a simulated, non-spherical acetabular socket. An unflanged standard component and a flanged standard component were compared to a custom design manufactured to match closely the simulated acetabular rim and provide a uniform cement layer of $2 \mathrm{~mm}$ thickness over the remainder of the surface (Figs 1 and 2) (7-9).

A model acetabulum of elliptical section was manufactured from acrylic resin to represent a typical shape presented at revision of total hip replacements. Pressure was measured at the 'floor' of the acetabulum (where the peak pressure was anticipated) using a piezoelectricdiaphragm type transducer (Druck PDCR-820). The 


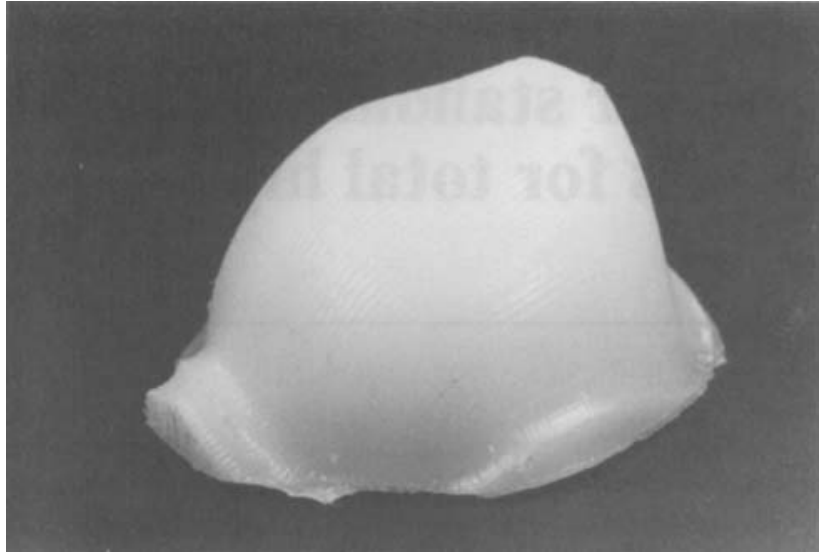

Fig. 1 Custom acetabular component machined from ultra high density polyethylene

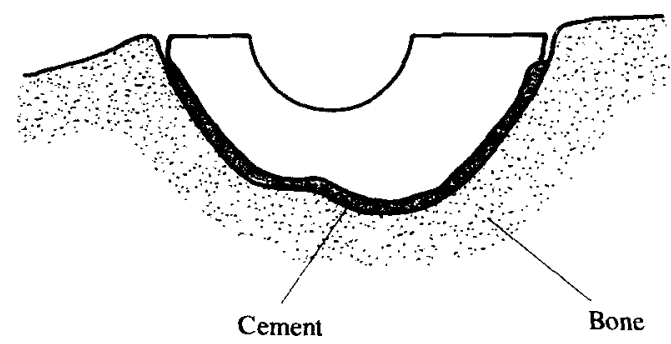

Fig. 2 Cross-section of custom component in acetabulum showing uniform cement layer and close fitting rim

output of this was connected to a digital pressure indicator (RS Components, UK) to allow immediate readings to be taken.

Cement penetration was measured at five points: one at the floor of the acetabulum, adjacent to the pressure transducer tapping, and four at points on the acetabular circumference, each approximately $10 \mathrm{~mm}$ from the acetabular rim (Fig. 3). Nylon tubes of $2 \mathrm{~mm}$ bore were passed through holes in the acetabular wall with their inner ends flared to seat in countersinks in the acetabu-

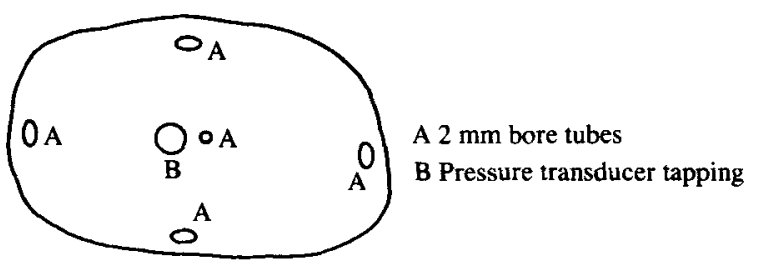

Fig. 3 Plan view of model acetabulum with positions of penetration tubes (A) and pressure tapping (B)

lum, thus remaining flush to the surface. The flared ends prevented displacement of the tubes by cement pressure and effectively sealed the joint to prevent fluid leakage at the measuring sites. The $2 \mathrm{~mm}$ bore was intended to be representative of the diameter of interstitial spaces in cancellous bone, as reported by $\mathrm{Oh}$ et al. (8). It is realized that this method of measuring cement penetration into cancellous bone is oversimplified and will not permit actual penetration distances to be predicted. However, it was decided that the method could indicate trends for penetration in this comparative study and had the virtue of being compatible with the work of $\mathrm{Oh}$. All five tubes were filled with liquid paraffin and connected to a manifold which, in turn, was attached to a $20 \mathrm{ml}$ syringe. Also connected to the manifold was a U-tube mercury manometer (Fig. 4). This arrangement was to enable a simulation of physiological systolic pressure which cement must overcome in vivo in order to achieve acceptable penetration into cancellous bone (6). Before each run of the experiment the system was pressurized to $3.3 \mathrm{kPa}(25 \mathrm{mmHg})$.

The components were loaded using a cast iron $10 \mathrm{~kg}$ crosshead guided by two vertical linear bearings, thus providing constant vertical loading of $98.1 \mathrm{~N}$ throughout each experiment (Fig. 5). This force is typical of that which could be sustained by a surgeon during cement polymerization. It was decided to control force for insertion since it has been noted that if the insertion rate is kept constant it is probable that unrealistically high forces will be generated with designs of components that effectively control cement flow and promote pressurization.

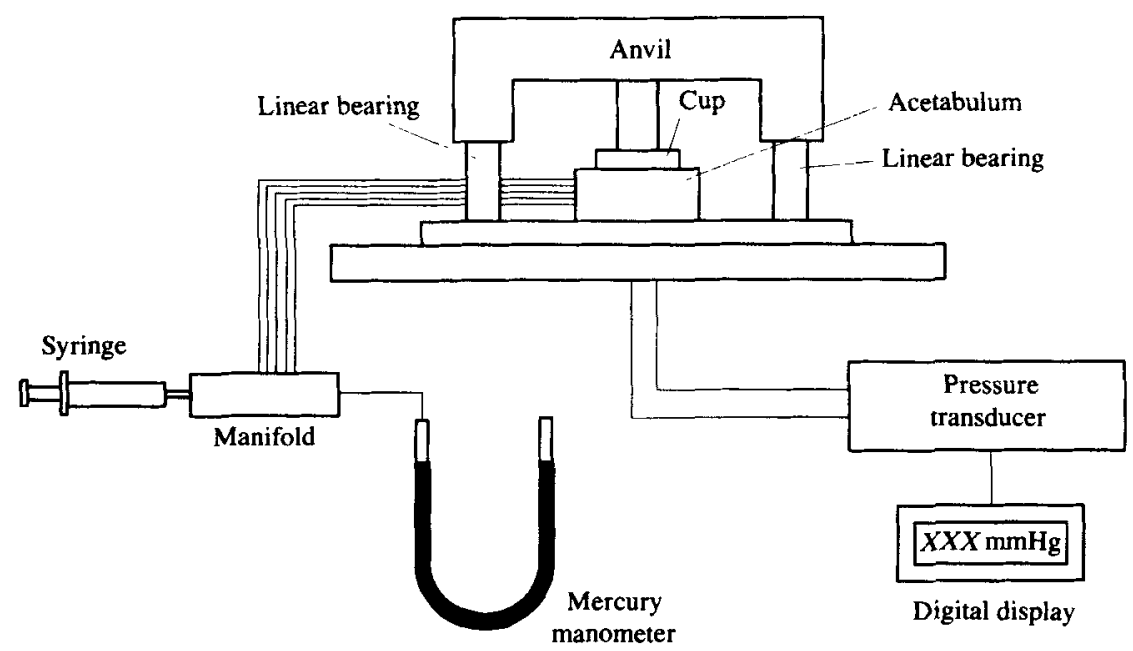

Fig. 4 Experimental apparatus and measurement systems 


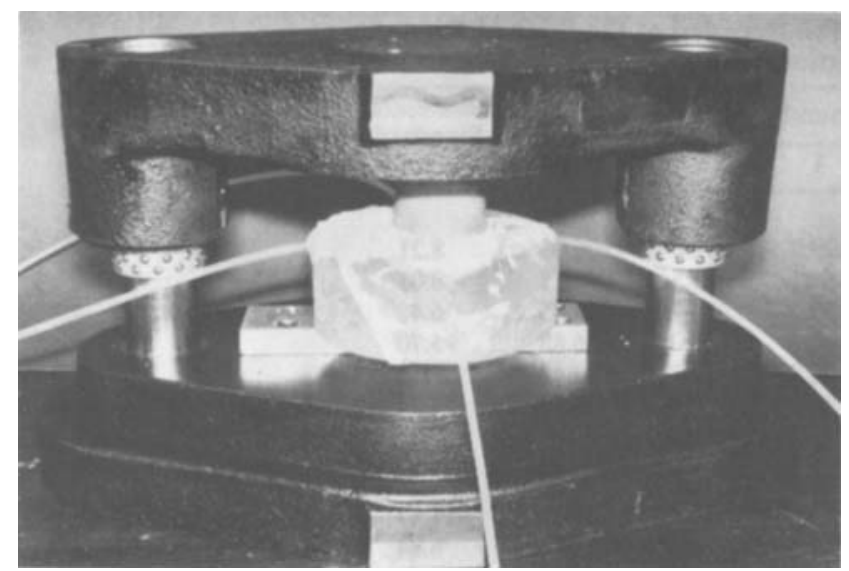

Fig. 5 Loading crosshead with model acetabulum, component and the four rim penetration tubes

\section{EXPERIMENTAL PROCEDURE}

The acetabular model was prepared by cleaning out residual cement from the previous experiment and insertion of new tubes for measurement of penetration. The tubes were connected to the manifold and filled with liquid paraffin (Fig. 4). The tube connecting the pressure transducer to the acetabulum was also filled with liquid paraffin to transmit pressure to the instrument.

Polymethylmethacrylate bone cement (Palacos, Schering-Plough, UK) was mixed by hand by one of the authors for 60 seconds and introduced to the acetabulum for insertion of the cup at 90 seconds from the start of mixing. The experiments were performed in a laboratory which was temperature controlled $\left(70^{\circ} \mathrm{F}\right)$ and the cement materials stored in this environment for at least 24 hours prior to the experiments.

On insertion of each component into the cemented cavity by means of the constant force from the crosshead the liquid paraffin in the tube was subjected to a pressure of $3.3 \mathrm{kPa}$, which was maintained manually throughout each experiment by reference to the mercury manometer. Initial placement of the component was performed by one of the surgeons who verified its position relative to the acetabular model. The unflanged components all had a continuous layer of cement around the rim, while the flanged and custom components assumed the same positions in each test as their introduction was guided by the geometry of the flange or rim. Pressure readings were noted at 30 second intervals after insertion and each test stopped at 165 seconds after insertion to facilitate cement removal prior to full polymerization. At this stage pressure trends had become clear and maxima identified. The pressures and penetration measurements were entered into a lap-top computer running a spreadsheet package (Lotus 123, Lotus Corporation, USA). This permitted tabulation, immediate production of graphs and analysis. Four experiments were completed for each of the three components tested.

\section{RESULTS}

Pressure measurements were recorded throughout the 12 experiments and are presented in Table 1. At each time interval after insertion the mean of the pressures from the set of four experiments for each component type were calculated together with the standard error. The means are plotted with reference to time of measurement in Fig. 6. The pressures for each component were compared using Student's $t$-test at 150 seconds from insertion. At this stage the pressure readings had stabilized from the higher values at insertion and further changes were not expected due to cement polymerization. The mean pressures of 20.73 and $17.05 \mathrm{kPa}$ for the standard and flanged components were not significantly different $(p=0.7)$; however, the custom component mean pressure of $68.5 \mathrm{kPa}$ was significantly higher $(p<0.005)$.

On termination of each experiment the polythene tubes were carefully withdrawn to measure the penetration of cement, which was taken to indicate the expected penetration into cancellous bone. The tubes were labelled and kept for future reference. The measurements recorded for each set of four experiments for the cups are presented in Table 2. The tubes close to the rim were grouped to determine an overall mean penetration at the margins of the acetabulum. The results from the acetabular floor were noted to indicate rather larger penetration measurements and these results had their mean calculated from the four measurements for each component. The means are presented in the form of bar charts in Fig. 7. Considering the floor penetration measurements for the custom and standard components there was no significant difference but both were significantly higher than the flanged component $(p<0.05)$. At the rim there was no significant difference in the cement penetration for the standard and flanged components but the higher penetration for the custom component was highly significant in comparison to either the flanged or unflanged component $(p<0.0001)$.

\section{DISCUSSION}

One aim of the custom acetabular design was to achieve enhanced pressurization of cement by the component itself during insertion. The experiments described were intended to make a direct comparison of custom and standard acetabular pressures by measuring their effects

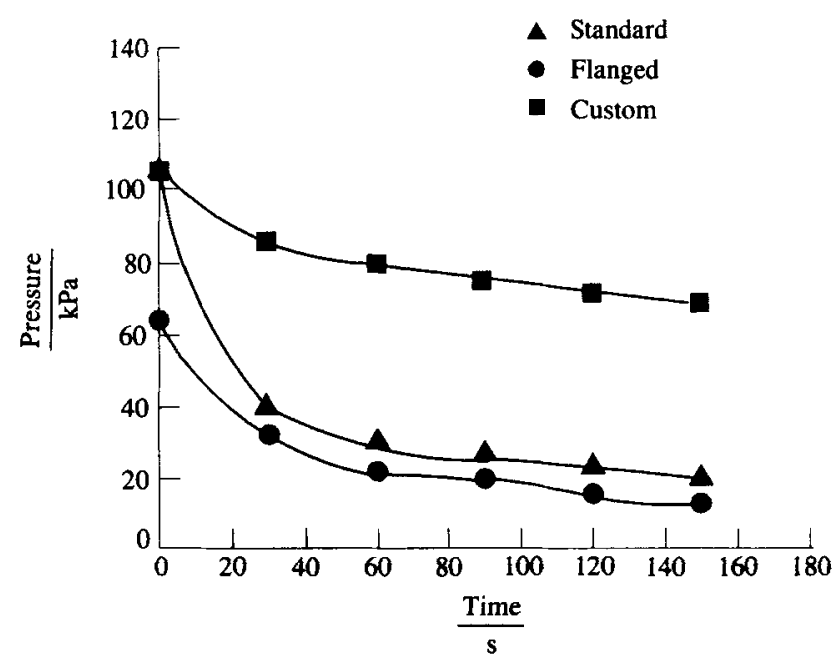

Fig. 6 Cement pressure measurements recorded at $30 \mathrm{~s}$ intervals 
Table 1 Cement pressure measurements $(\mathrm{kPa})$ recorded at the floor of the acetabulum during cement polymerization

\begin{tabular}{|c|c|c|c|c|c|c|}
\hline \multirow{2}{*}{$\frac{\text { Time from insertion }}{\mathrm{s}}$} & \multicolumn{4}{|c|}{ Experiment number } & \multirow[b]{2}{*}{ Mean } & \multirow{2}{*}{$\begin{array}{l}\text { Standard } \\
\text { error }\end{array}$} \\
\hline & 1 & 2 & 3 & 4 & & \\
\hline \multicolumn{7}{|l|}{ Unflanged standard cup } \\
\hline 0 & 90.1 & 91.5 & 129.9 & 112.6 & 106.03 & 8.21 \\
\hline 30 & 33.4 & 27.8 & 68.2 & 33.5 & 40.73 & 8.01 \\
\hline 60 & 26.4 & 24.2 & 53.5 & 21.7 & 31.45 & 6.42 \\
\hline 90 & 23.8 & 21.7 & 46.0 & 16.0 & 26.88 & 5.70 \\
\hline 120 & 22.0 & 19.5 & 40.2 & 12.2 & 23.48 & 5.15 \\
\hline 150 & 20.3 & 17.6 & 35.6 & 9.4 & 20.73 & 4.74 \\
\hline \multicolumn{7}{|l|}{ Flanged cup } \\
\hline 0 & 70.0 & 32.0 & 79.6 & 68.8 & 62.60 & 9.08 \\
\hline 30 & 72.3 & 12.1 & 21.3 & 21.0 & 31.68 & 11.87 \\
\hline 60 & 45.5 & 10.2 & 17.5 & 14.3 & 21.88 & 6.94 \\
\hline 90 & 39.9 & 9.8 & 15.7 & 10.9 & 19.08 & 6.11 \\
\hline 120 & 38.4 & 9.9 & 14.7 & 8.2 & 17.80 & 6.06 \\
\hline 150 & 37.8 & 10.0 & 14.2 & 6.2 & 17.05 & 6.15 \\
\hline \multicolumn{7}{|l|}{ Custom cup } \\
\hline 0 & 140.0 & 85.0 & 107.5 & 87.9 & 105.10 & 10.96 \\
\hline 30 & 97.0 & 86.2 & 75.5 & 84.2 & 85.73 & 3.83 \\
\hline 60 & 81.9 & 87.0 & 75.5 & 73.4 & 79.45 & 2.68 \\
\hline 90 & 77.8 & 86.1 & 74.7 & 66.1 & 76.18 & 3.58 \\
\hline 120 & 75.3 & 85.3 & 71.3 & 56.2 & 72.03 & 5.23 \\
\hline 150 & 73.7 & 84.5 & 67.4 & 48.4 & 68.50 & 6.56 \\
\hline
\end{tabular}

on penetration. The pressure measurements were restricted to one site, due to only one transducer being available; however, the pressure-time characteristics for each design demonstrate differences which may be further explained by observations made during the experiments. The unflanged component recorded a relatively high initial pressure (mean $106 \mathrm{kPa}$ ), but this occurred due to the component sinking rapidly through the cement and almost occluding the transducer orifice. The pressure decayed rapidly after 'bottoming out' had occurred. The flanged component did not generate such a high pressure initially and in a similar way the pressure decayed. It was noted that the flanges, which had been trimmed by one of the surgeons in the usual fashion, made contact with the acetabular wall and were sufficiently stiff to oppose the insertion force. The flanges became effective in restricting cement flow as it approached its final position, but impingement prevented continuation of the pressure rise and its maintenance during curing. The custom component recorded a high initial pressure (mean $105 \mathrm{kPa}$ ), yet unlike the previous designs the pressure decayed much more slowly during polymerization. This was attributed to the component closely matching the acetabular rim and preventing the escape of cement, yet the walls of the acetabulum were almost parallel with the insertion direction so no support was available from direct impingement. The custom rim does ensure correct posi-

Table 2 Penetration measurements (mm) made at the floor and at four points around the rim of the acetabulum

\begin{tabular}{|c|c|c|c|c|c|}
\hline Experiment & Floor & Inferior & Left & Superior & Right \\
\hline \multicolumn{6}{|l|}{ Unflanged standard cup } \\
\hline 1 & 15.2 & 2.9 & 7.7 & 6.6 & 7.6 \\
\hline 2 & 7.2 & 6.6 & 7.5 & $*$ & 5.1 \\
\hline 3 & 10.6 & 3.5 & 9.6 & 4.2 & 5.8 \\
\hline 4 & 13.4 & 3.5 & 10.2 & 4.1 & 9.8 \\
\hline Mean (floor) 11.6 & \multicolumn{5}{|c|}{ Mean (rim) 6.2} \\
\hline Standard error (floor) 1.5 & \multicolumn{5}{|c|}{ Standard error (rim) 1.2} \\
\hline \multicolumn{6}{|l|}{ Flanged cup } \\
\hline 1 & 6.2 & 11.0 & 10.6 & 13.5 & 8.6 \\
\hline 2 & 4.5 & 4.9 & 4.0 & 5.2 & 4.5 \\
\hline 3 & 6.2 & 6.2 & 4.3 & 7.4 & $*$ \\
\hline 4 & 4.0 & 4.7 & 7.6 & 4.9 & 4.0 \\
\hline Mean (floor) 5.2 & \multicolumn{5}{|c|}{ Mean (rim) 6.7} \\
\hline Standard error (floor) 0.5 & \multicolumn{5}{|c|}{ Standard error (rim) 1.5} \\
\hline \multicolumn{6}{|l|}{ Custom cup } \\
\hline 1 & 14.7 & 14.7 & 13.9 & 12.7 & 13.9 \\
\hline 2 & 26.6 & 14.9 & 16.5 & 14.5 & 12.6 \\
\hline 3 & 13.1 & 14.5 & 11.0 & 12.1 & 11.0 \\
\hline 4 & 13.2 & 15.3 & 13.7 & 14.8 & 10.5 \\
\hline Mean (floor) 16.9 & \multicolumn{5}{|c|}{ Mean (rim) 13.6} \\
\hline Standard error (rim) 2.8 & \multicolumn{5}{|c|}{ Standard error (rim) 0.9} \\
\hline
\end{tabular}

* Missing values. 


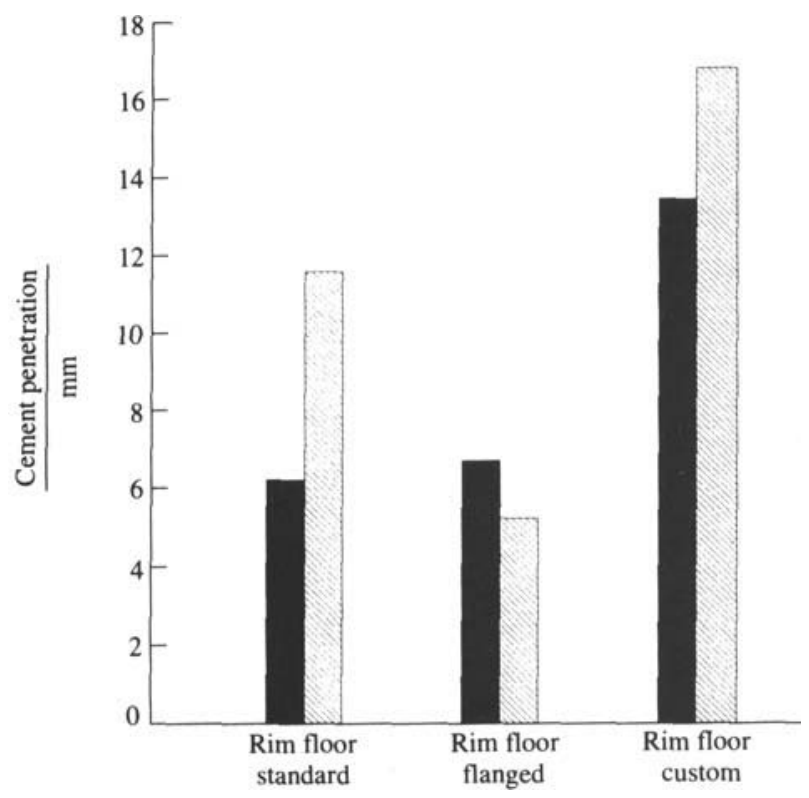

Fig. 7 Cement penetration recorded after cement polymerization

tioning for a uniform thickness of cement mantle. The insertion force was opposed by the pressure maintained in the cement. On removal of the custom component after each experiment it was noted that 'bottoming out' had not occurred and that its surface was covered by a cement layer of uniform thickness.

The penetration measurements were intended to demonstrate the expected behaviour of the cement in infiltrating cancellous bone. As such the measurements should be considered in a comparative rather than absolute sense. Some attempt was made to make the method more realistic by representing blood pressure to oppose cement flow. The penetrations at the floor of the acetabulum reflect the initial maximum pressure relationship for each component. The penetration for the custom component remained high since cement pressure was maintained much more effectively. However, the benefits of the custom component in causing higher penetration close to the rim is clearly demonstrated, whereas the standard designs failed to achieve such penetration close to the edge of the cement layer where there is insufficient material to resist escape. It is proposed that the fixation of the custom component will be much more secure around the rim, with forces being transmitted effectively to a larger area of bone. These results indicate that the custom principle has the potential to make the most of opportunities for fixation by penetration of cement at the bone interface The desired depth of penetration into bone has not been studied, but it is realized that excessive penetration may cause necrosis due to exothermic polymerization. If the aims of uniform cement mantle with increased pressures during curing are realized, these may prompt further research into factors affecting fixation, including cement thickness.

\section{CONCLUSIONS}

The custom component design has been demonstrated to maintain higher cement pressure during polymerization within an irregular acetabulum compared to standard designs. Cement penetration into cancellous bone is expected to be enhanced, especially around the rim of the acetabulum. The cement layer was observed to be continuous and of uniform thickness with no evidence of direct component/bone contact. The authors conclude that the custom design achieves the aim of improving cement pressurization, which could be expected to lead to better fixation.

\section{REFERENCES}

1 Charnley, J. The bonding of prostheses to bone by cement. J. Bone Ji Surg., 1964, 46-B, 518.

2 Gruen, T. A., Markolf, K. L. and Amstutz, H. C. The effects of lamination and blood entrapment on the strength of acrylic bone cement. Clin. Orthop. Related Res., 1976, 119, 250.

3 Lee, A. J. C., Ling, R. S. M. and Vangala, S. S. Some clinically relevant variables affecting the mechanical behaviour of bone cement. Arch. Orthop. Traumatic Surg., 1978, 92, 1.

4 Lee, A. J. C. and Ling, R. S. M. A device to improve the extrusion of bone cement into the bone of the acetabulum in the replacement of the hip joint. Biomed. Engng, 1974, 9. 1.

5 Charnley, J. Long term radiological results. In Low friction arthroplasty of the hip, Vol. 94, 1979 (Springer Verlag, Berlin).

6 Shelley, P. and Wroblewski, B. M. Socket design and cement pressurisation in the Charnley low-friction arthroplasty. J. Bone Jt Surg., $1988,70-B, 358$.

7 Chua, K. T. Manufacture of customised sockets for hip joint replacements. MSc thesis, The Queen's University of Belfast, Belfast, 1990.

8 Oh, I., Sander, T. W. and Treharne, R. W. Total hip acetabular cup flange design and its effect on cement fixation. Clin. Orthop. Related Res., 1985, 195, 304.

9 Beverland, D. E., Kernohan, W. G., Nixon, J. R., Orr, J. F. and Watson, P. The manufacture and evaluation of custom acetabular sockets. IMechE Conference on Joint replacements in the $1990 \mathrm{~s}$, 1992, paper C441/002, pp. 65-68 (Mechanical Engineering Publications, London). 